Article

\title{
Analysis of the Vulnerability and Resilience of the Tourism Supply Chain under the Uncertain Environment of COVID-19: Case Study Based on Lijiang
}

\author{
Haixia Bai ${ }^{1,2}$ (D) and Wenxue Ran ${ }^{3, *}$
}

Citation: Bai, H.; Ran, W. Analysis of the Vulnerability and Resilience of the Tourism Supply Chain under the Uncertain Environment of COVID-19: Case Study Based on Lijiang. Sustainability 2022, 14, 2571. https:// doi.org/10.3390/su14052571

Academic Editor: Juan

Ignacio Pulido-Fernández

Received: 20 January 2022

Accepted: 20 February 2022

Published: 23 February 2022

Publisher's Note: MDPI stays neutral with regard to jurisdictional claims in published maps and institutional affiliations.

Copyright: (C) 2022 by the authors. Licensee MDPI, Basel, Switzerland. This article is an open access article distributed under the terms and conditions of the Creative Commons Attribution (CC BY) license (https:// creativecommons.org/licenses/by/ $4.0 /)$.
1 School of Business, Yunnan University of Finance \& Economics, Kunming 650221, China; baihaixia01@stu.ynufe.edu.cn

2 Tourism and Economic Management Department, Lijiang Teachers College, Lijiang 674199, China

3 School of Logistics, Yunnan University of Finance \& Economics, Kunming 650221, China

* Correspondence: ranwxa@ynufe.edu.cn

\begin{abstract}
The uncertainty environment brought about by COVID-19 has broken the original stable hierarchical network structure and the whole supply and demand system of the tourism supply chain (TSC), which has brought heavy losses to the tourism industry. Using the case research and consensual qualitative research (CQR) method, taking the real situation and perception of individual supply chain members as a window, supplemented by the narrative insertion of Lijiang Yulong Tourism Co., Ltd., Lijiang Old Town and Yulong Snow Mountain scenic areas, the general laws of the vulnerability and resilience of the TSC were glimpsed. The results show that there are vulnerability factors in the TSC including the supply side, demand side, government side, destination economic structure and supply chain attributes, which lead to the interruption and damage of the TSC after the outbreak of the pandemic. At the same time, China's overall economic environment, tourism demand side, supply side, government side and market participants all have resilience elements. Behind the vulnerability, there is a power of recovery and opportunities for innovation and change. The TSC shows a trend of restorative growth. Theoretically, it helps to enrich theories of TSC and supply chain management under an emergency crisis. In practice, the response behavior of participants at different levels of the supply chain is also the basis for TSC risk management and formulation of optimization strategies in the future, which helps tourism sustainable development in the uncertain environment.
\end{abstract}

Keywords: tourism supply chain; supply chain vulnerability; supply chain resilience; uncertain environment; tourism sustainability

\section{Introduction}

Tourism industry has been hit by many health crises since the beginning of the 21st century, such as SARS, Ebola and MERS pandemics, which have brought varying degrees of impact on national or regional tourism. COVID-19, in particular, has been ongoing since the end of 2019 and continues to oscillate worldwide. Now the crisis has reached an unprecedented scale, which has greatly affected the world, including China's tourism economy. In order to control the pandemic, in addition to relying on restraining measures such as expanding social distance, wearing masks, using health QR codes and big data tracking trips, the Chinese government has implemented strict and comprehensive border restrictions and regional blockade measures, which will undoubtedly have a serious shortterm negative impact on tourism investment and consumption, as well as the supply chain sustainability [1]. Although forecasting departments and practices have proved that no commercial organization can be completely immune from COVID-19's influences, different commercial sectors are affected differently due to different industry characteristics, demand and supply modes [2]. Service industries that rely heavily on mobility, such as tourism, are the first to be affected. According to the statistical bulletin on national economic and 
social development released on the website of the National Bureau of Statistics, China's domestic tourism revenue was CNY 2228.6 billion in 2020, a decrease of $61.1 \%$ over the previous year.

From the perspective of the tourism industry, the negative impact caused by COVID19 has been transmitted step by step along the supply chain supply side-demand side in both directions, causing huge social impact and economic losses. Firstly, numerous industries' supply chains are interrupted, which will affect the stability of employment and personal income and increase people's travel economic pressure and psychological insecurity, thereby reducing tourism demand and consumption expenditure. Then, the reduction in demand is passed through the reverse TSC, the production shrinkage signal is transmitted level by level, tourism supply enterprises at all levels have excess capacity and idle production resources, and normal production cannot continue. Lastly, homogeneous tourism supply enterprises compete for limited demand, and competition intensifies. Many tourism companies are facing the risk of suspension, closure, bankruptcy or interruption of cooperation, the original stable tourism supply-production-consumption network system is broken, and the vulnerability of the tourism supply chain emerges. The good order and trend of tourism sustainable development are disrupted, and the future trend and economic operation efficiency of the tourism market become uncertain and difficult to predict.

The frequent occurrence of uncertain events and the serious consequences brought by the vulnerability of the TSC mentioned above prompt researchers in various fields to turn their attention to supply chain resilience (SCR) that helps minimize the instability caused by emergencies [3], who then try to seek good countermeasures from the perspective of their own disciplines [4]. Supply chain resilience is considered to be an important strategic capability of an enterprise $[5,6]$ enabling enterprises to predict, adapt, respond and quickly recover from unpredictable events. SCR implies the concept of sustainability [7], which not only deals with a single uncertain event but is also a core ability to continuously predict and adjust the organizational mechanism in the face of sudden changes in order to maintain the sustainable profit potential of enterprises, whose objective is the stable supply chain structure and the actors' sustainable development.

Combing the existing relevant literature, it is found that there are more studies on SCR outside China that either quantitatively evaluate industry SCR or empirically explore the variables impacting SCR, then seek strategies to improve it. However, most of the previous studies focused on the manufacturing industry [8], the exploration of the service industry is limited, and focused and in-depth research on the tourism industry is even rarer. Tourism under the pandemic themes focuses most on hotels, with only a little attention paid to climate change, forest resources and cities' recovery and sustainable development. Research in China focuses on tourism risk or crisis management, such as the impact of the pandemic and recovery countermeasures, tourists' psychology, behavior and management suggestions, tourism industry changes and forecast, etc. However, study related to the supply chain and sustainability is quite lacking. As of September 16, 2021, when we started this paper, we used "pandemic, tourism supply chain resilience" or even "tourism supply chain resilience" and "tourism supply chain, sustainable" as keywords to search in the "Academic Journals" column of CNKI; the result was 0.

To sum up, few scholars pay attention to the multiple subjects and influencing factors of tourism sustainable development in the COVID-19 uncertain environment from the perspective of the supply chain, and the existing research on the tourism supply chain is still sporadic and fragmented, similar to a patchwork of multidisciplinary irrelevant theories [9]. Furthermore, a too-concentrated tourism perspective will result in a narrow scope of research, which is not conducive to the collision and diversified development of thinking and poses a challenge to the academic direction of the tourism field. In terms of research methods, most studies are based on second-hand or statistical data, lacking first-hand data and detailed records from tourism destinations, and the application of qualitative research methods is rare. 
Therefore, based on supply chain theory, using the case study method, this paper aims to describe and present the real production and living conditions of the tourism industry and its practitioners under COVID-19 in Lijiang, a small city with tourism as its pillar industry located in Southwest China, and objectively reflect the dual existence of the vulnerability and resilience of the tourism supply chain. Through the interdisciplinary perspective of the tourism supply chain, we put forward a tourism supply chain vulnerability-resilience framework, which systematically and comprehensively lists the positive and negative antecedent variables affecting the sustainable development of tourism, to comprehensively understand and seek solutions to the risks and challenges brought about by the COVID-19 uncertain environment from different perspectives so as to rebuild tourism sustainability.

This article contributes by further enriching TSC and supply chain management theories under emergencies or crises. In practice, it summarizes the valuable experience that is helpful to the recovery of the tourism industry from the perspectives of all actors so as to provide useful implications for management practices such as multi-agent participation, decision makers' enlightenment, formulation of reasonable mitigation strategies and risk management practices in the future to better deal with various kinds of unpredictable environmental changes. On the macro level, it provides a real microscopic lens for the world to see China under the pandemic. On the micro level, it helps all parties in the TSC to see the impact of COVID-19 on other parties and the efforts they made for sustainable reconstruction, which is conducive to enhancing the tolerance and understanding among multiple parties in the supply chain.

Meanwhile, we adopt methods of observation and direct dialogue with tourism practitioners and narrative analysis, which is not only authentic but also makes the article more lively and vivid, as opposed to obscure and tedious which academic research usually is.

The remainder of this paper is structured as follows. Section 2 briefly reviews the literature to clarify the theoretical basis of this article. Section 3 introduces the methods and data sources we used. The main results are described in detail in Section 4. Finally, Section 5 concludes with a conceptual framework diagram and discusses the limitations as well as further research directions.

\section{Literature Review}

\subsection{Tourism Supply Chain}

In 1975, United Nations World Tourism Organization published a report on the distribution channels of the tourism industry [10], paying attention to the service network from the perspective of tourism distribution, which was an integral part of the supply chain; this was regarded as the earliest research on the tourism supply chain. Then, it was not until the beginning of the 21st century that Scavarda [11], Page [12], Tapper and Fond [13] and Yilmaz \& Bititci [14] took the lead in carrying out descriptive research on the tourism supply chain (TSC) or its similar concepts (such as tourism value chain, tourism industry chain), and tourism supply chain research became gradually enriched. Among them, Tapper and Font put forward the most mature definition of the tourism supply chain in the early stage. They believed that the tourism supply chain includes all (direct and indirect) suppliers of goods and services that meet the needs of tourists in the tourism product supply system, including upstream supplier services such as infrastructure construction, water and electricity supply, food production, garbage disposal, laundry services and basic services suppliers such as transportation, accommodation, scenic spots, catering and tourist commodities (tourist souvenirs, handicrafts). Then, Zhang et al. [15] further expanded it based on this, defining the TSC as a network of tourism organizations, including a supply side containing different components of tourism products/services and a distribution side that includes marketing the final tourism products to tourists and stakeholders such as participants in the private and public sectors.

At present, the TSC perspective is becoming a new research direction of tourismrelated research. There are more and more TSC studies in China and abroad, focusing on the topics of the supply chain conceptual model and structure [16], supply chain 
management and upstream-downstream competition and cooperation [17], green tourism supply chain [18] and smart tourism supply chain [19]. The exploration of supply chain themes continues to expand and deepen. Sigala [20] discussed the applicability of a supply chain management framework for enhancing tourism sustainability using a tour operators' case study. Ma et al. [18] discussed the role of big data in enabling low-carbon, smart and sustainable tourism supply chains. However, overall, research on sustainable development is quite rare.

Based on the existing literature and the continuous integration of new technologies, new ideas and new features in recent years, tourism supply chain refers to a tourism supply and demand system relying on tourism resources, with tourism providers, tourism suppliers and tourism integrators (or operators) as the main body and joint participation by the government, tourism management departments, communities, industry associations and other stakeholders to meet the needs of tourists' goods and services under multiple channels. Tourism supply chain, which is essentially the same as a supply chain, emphasizes a comprehensive view of multiple actors and their interactive relations in the chain. As actors, tourists, tourism management departments and various micro market entities (including tourism enterprises, communities, the public, non-governmental organizations, educational institutions, etc.) are a unity of interests of the TSC, externally, affected by various environments and, internally, sharing the same market and multi-directional interaction, with energy flow and material circulation, and constitute a complex organic whole, moving toward an increasingly balanced sustainable development of economy, ecology and environment.

\subsection{Supply Chain Resilience}

According to Walker and Salt's summary, the concept of resilience originated from the fields of ecology, psychology, engineering and disaster relief [21] (Walker \& Salt, 2012). Scholars borrowed these concepts when defining supply chain resilience. The concept of supply chain resilience (SCRES) was put forward in 2003 by Rice \& Caniato [22] when they conducted a follow-up research study on two important reports on supply chain response to terrorism by MIT and Cranfield University.

Early research on supply chain resilience focused on the adaptability and restoration ability of supply chains during and after a crisis [5,22-24]. Later, scholars shifted their perspective to pre-crisis. Ponomarov \& Holcomb [25] first focused on the pre-event stage in the definition of resilience, emphasizing the preparation for unpredictable events through proactive planning and design of supply chain network; Ponis \& Koronis [26] and Day [27] then proposed the need for risk prediction and impact reduction before a crisis occurs. Next, elements of resilience preparation and seeking growth were incorporated. Hohenstein [28] proposed to take advantage of the opportunities that may arise after a crisis to seek customer service, market share and financial performance growth. Aslam et al. [29] empirically discussed the positive impact of supply chain ambidexterity (supply chain alignment and adaptability) on increasing supply chain resilience.

The outbreak of COVID-19 fully exposed the vulnerability of the tourism supply chain, changed the way scholars view tourism and turned their attention from the tendency of continuous expansion to the supply chain resilience, which is dedicated to the protection and restoration of the tourism industry [3]. Belhadia \& Kamble [30] evaluated the supply chain resilience of the automobile industry and airline industry, respectively, and proposed short-term and long-term response strategies according to the level of resilience. Arbulú et al. [31] used Monte Carlo simulations to measure the economic risks and vulnerability of the Balearic Islands to the COVID-19 crisis. Trabucco [32] advocated adopting lean mechanisms and digitalization of the supply chain to achieve business resilience and sustainability under the COVID-19 background. It can be observed that tourism research on supply chain resilience in the true sense is rather modest. The interaction between supply chain resilience and tourism sustainability is usually mentioned as the research significance but less as the research theme. 
In addition, although the vulnerability of tourism is a concept widely recognized and familiar with in the tourism industry and is often discussed in the study of tourism during COVID-19, few articles deeply analyze its roots and specific manifestations. The vulnerability of the TSC is the degree to which the tourism supply chain is vulnerable to damage when facing risks, the resilience of the TSC refers to the ability of the tourism supply chain to adapt, respond, recover and grow when facing a destructive and uncertain environment. These two can be regarded as two sides of the coin of the TSC; surprisingly, few scholars discuss and compare them in the same article.

The above shortcomings have left a gap in the research and therefore became our research question.

\section{Methodology}

A case study methodology was adopted in this paper as it is deemed as a good methodology for sustainable supply chain research [33] that not only enables rich data collection during different stages but can also present a real context for the analysis object and research phenomenon [34] and provide multiple sources of evidence for inductive and partially deductive approach [35].

Narrative analysis is an important technique we used to analyze the vulnerability and resilience of TSC. Narrative research is based on the theoretical paradigm of constructivism, through the protagonist's oral narration of their own experience or related events, to understand the real experience of individuals or groups in social life and practice that then combines these scattered and disconnected stories in an interpretative way to analyze a specific social phenomenon from a macro perspective [36]. Thus, it can help to deeply understand the real situation and perception of social individuals under the pandemic situation and, taking multiple industries involved in tourism as a window, to get a glimpse of the overall picture and general rules of the TSC.

\subsection{Data Acquisition}

The data, on the one hand, came from field observations by the project team, recording the diachronic states and changes of Lijiang tourism under the pandemic. From January 2021, the project team members took turns to enter Lijiang Old Town 1-2 times a week, took photos of the intelligent big data screen that was located near the entrance and recorded the real-time number of tourists displayed on it (see Appendix A). We also used direct observation method to perceive, track and record the development and changes of tourism under the pandemic situation. Lijiang Old Town was chosen because it is one of the most classic tourist attractions in Lijiang and does not charge tickets. It is a must-visit place for all visitors to Lijiang, which represents the development level and is also a window into the whole tourism situation of Lijiang. Meanwhile, our team also visited other tourism hot spots, such as Shuhe ancient town and Yulong Snow Mountain, as well as kept an eye on performing arts such as Lijiang Water and Sands and Eternal Love through media and social relations so as to ensure a comprehensive understanding of all levels and subjects of Lijiang tourism supply chain.

On the other hand, data were obtained through semi-structured interviews with tourism practitioners. The interview outline included three parts: (1) basic information of the interviewees, (2) the impact of the pandemic on their work and life and (3) their countermeasures. A total of 168 people in Lijiang from government, different tourist destinations or scenic spots, travel agencies, restaurants, accommodation industry as well as tourists were interviewed. The interview adopted a semi-structured approach, which can not only ensure that the interview questions have sufficient coverage and correct ethical procedures but also facilitate the respondents to express freely and supplement information. For the purpose of confidentiality and anonymity, we hid their company names and replaced their names with number codes. This stage lasted about 6 months, from March to September 2021. Some interviews were conducted face-to-face; the others were conducted remotely by telephone or online communication tools. Based on the principle of 
efficient interview and reducing disturbance, the time for each interview was controlled at 20-40 min. With the permission of the interviewee, the interview contents were recorded by audio recording or taking notes to ensure the reliability and internal validity of the data.

\subsection{Data Analysis}

Since the concept of supply chain originates from manufacturing industry and is a research field of logistics, tourism supply chain research is interdisciplinary and lacks relevant analysis tools. This paper used the consensual qualitative research (CQR) method in the field of counseling psychology to analyze data. CQR is a qualitative research method based on constructivism [37], which can not only provide vivid, rich and full description for the natural case destination [38], but also remain open to "discover" ideas, relationships and concepts rather than preconceived hypotheses [39]. It is a process in which multiple researchers rely on language itself and the background information of the whole case to understand the phenomenon, make inferences and gradually reach an agreement to draw a conclusion [40]. Its core elements are as follows: (1) use of semi-structured open questions to collect data; (2) multiple researchers discuss repeatedly until agreement is reached in the process of data analysis; (3) at least one inspector; and (4) data analysis units include core idea, domain and category [41].

Thus, firstly, we set 2 tourism experts, 2 supply chain experts and 1 interdisciplinary background scholar in our team as researchers to form a research group in order to enrich the team's perspective and try our best to eliminate the subjective bias of a single researcher by relying on the consensus of researchers with diverse backgrounds. The remaining 2 members of the team were separated from the research materials to act as inspectors. The experience of both parties was modified and supplemented to ensure the accuracy of the conclusions.

Next, we analyzed data following the phase sequence of "core idea-domain-category". In the first stage, in-case analysis, each researcher read the data independently, summarized and refined the language of each interview's content without changing the original intention, extracted the core idea and summarized it into a brief narrative. In the second stage, combined with the study theme of this paper, the core ideas obtained in the previous stage were divided into two domains, namely supply chain vulnerability and supply chain resilience. Then, in the third stage, cross-analysis, group members repeatedly read and discussed together, combining their own knowledge, experience and understanding, to try to extract all case content under each domain into different categories and sub-categories.

Consensus was essential as it protects against researcher bias, thereby improving trustworthiness [40]. After each task, the group members gathered together to discuss, repeatedly modify or adjust the division and definition of the core idea (or themes, categories) until an agreement was reached. Then, they submitted the results to the inspector for review; meanwhile, they accepted the questions raised by the inspector and returned to the group for reconsideration. This was repeated over and over again until they, finally, came to a conclusion.

In addition, in order to break the monotony of the research subject, method and content, two cases were inserted in the narrative process. The first case was Lijiang Co., Ltd., which recorded the major events of tourism enterprises represented by it from January 2020 to October 2021. The second case took Lijiang Old Town as the main body and recorded the scenic spot stories represented by it.

\section{Result}

A TSC vulnerability-resilience framework was put forward as shown in Figure 1. 


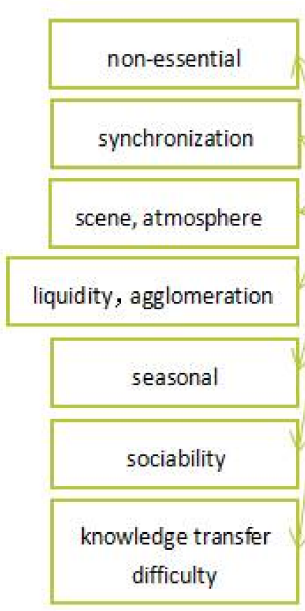

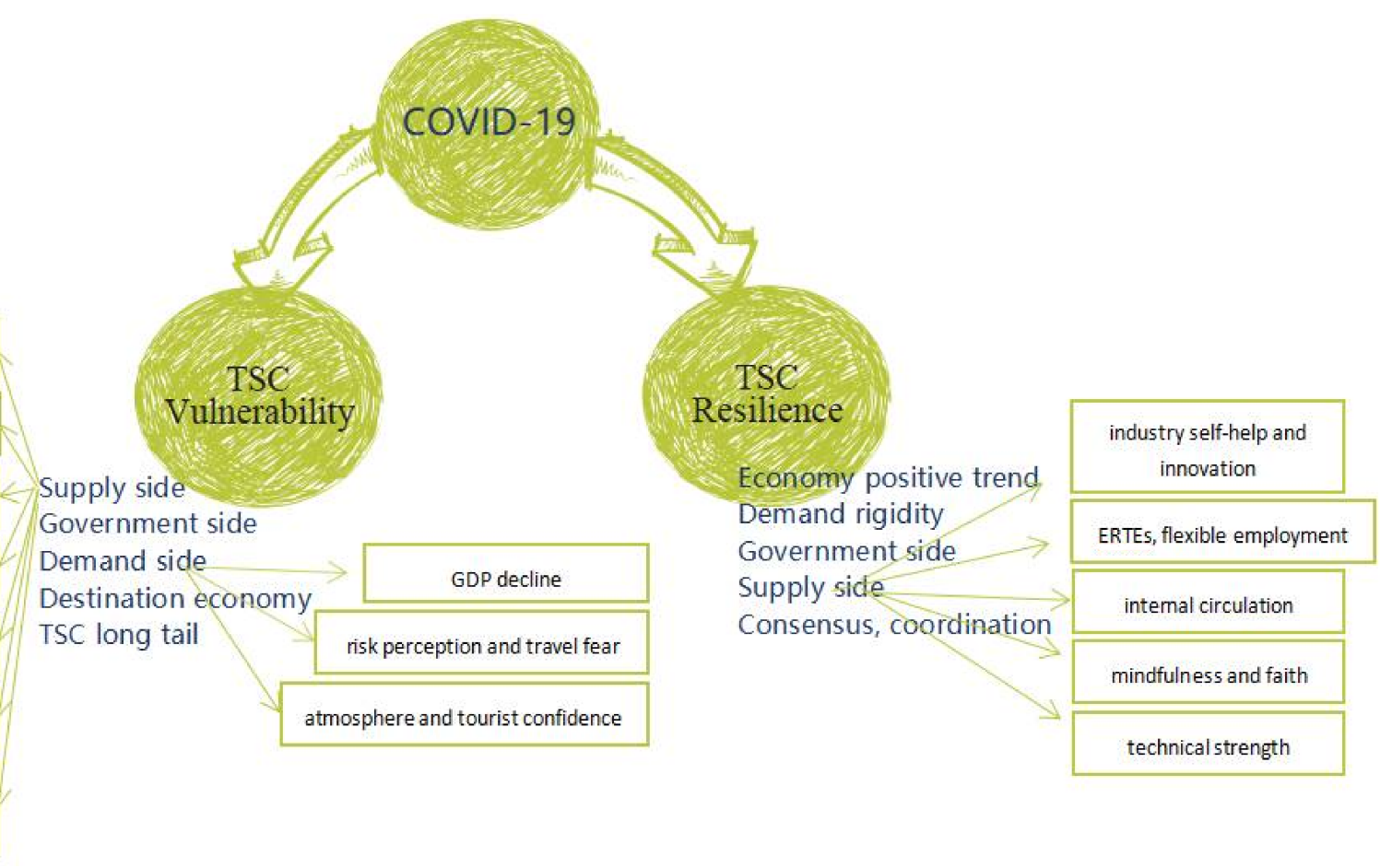

Figure 1. TSC vulnerability-resilience framework.

\subsection{TSC Vulnerability}

According to the definition of Turner II et al., tourism vulnerability refers to the extent to which a tourism destination may suffer damage due to accidental exposure to risk [42]. Some inherent characteristics at each side of the TSC increase its vulnerability to nonsystematic exogenous risks such as a health crisis, natural disasters and socio-political disasters. The vulnerability analysis of Lijiang's TSC (see core idea in Table 1) is as follows.

Table 1. TSC vulnerability core idea.

\begin{tabular}{|c|c|c|}
\hline Time & Interviewee & Brief Narrative \\
\hline January 2021 & $\begin{array}{c}\text { G-03 } \\
\text { Administrative staff of the } \\
\text { Tourism Bureau }\end{array}$ & $\begin{array}{l}\text { In order to ensure the safety of tourists, all scenic spots in Lijiang have } \\
\text { implemented strict pandemic prevention and control measures of "limit, } \\
\text { peak staggering, appointment" according to the requirements of the } \\
\text { authority. For example, the Lugu Lake scenic spot has implemented } \\
\text { Sichuan-Yunnan jointly measures to limit the flow of tourists, Yulong Snow } \\
\text { Mountain scenic area set a maximum daily capacity at } 43,500 \text {, once reached, } \\
\text { stop selling tickets, the tourist reception of Lijiang Old Town cannot exceed } \\
75 \% \text { of its maximum capacity, and the flow should be strictly controlled. }\end{array}$ \\
\hline March 2021 & $\begin{array}{c}\text { TA-02 } \\
\text { Travel agency executive }\end{array}$ & $\begin{array}{l}\text { From January to July } 2019 \text {, we received about } 200,000 \text { tourists, but only } \\
80,000 \text { in the same period this year. During the past six months, the } \\
\text { pandemic spread from Ruili to Nanjing and then to Zhangjiajie, the } \\
\text { butterfly effect brought by the repeated outbreak has made Lijiang tourism } \\
\text { like the stock market, alternately turning red and green. } 2020 \text { was } \\
\text { supposed to be tough, but unexpectedly, this year (2021) was even tougher. }\end{array}$ \\
\hline April 2021 & $\begin{array}{c}\text { Ac-05 } \\
\text { Innkeeper }\end{array}$ & $\begin{array}{l}\text { In two years, I lost } 1 \text { million (yuan). This year, I have to pay } 4 \text { years' rent to } \\
\text { the landlord in a lump sum. I tried to negotiate with the landlord to pay it } \\
\text { in two years, but was rejected. Alas, it won't work if I don't pay, more than } \\
\text { two million was invested in the decoration, it is really a dilemma. The boss } \\
\text { next door has stayed here for nearly } 20 \text { years, but this year, he can't stand it } \\
\text { anymore. His rent was just due and he went back to his hometown. I don't } \\
\text { even have a chance to go back doing manual work. }\end{array}$ \\
\hline
\end{tabular}


Table 1. Cont.

\begin{tabular}{|c|c|c|}
\hline Time & Interviewee & Brief Narrative \\
\hline April 2021 & $\begin{array}{l}\text { G-01 } \\
\text { Government worker }\end{array}$ & $\begin{array}{l}\text { Under the pandemic, "stabilizing employment" in the tourism industry } \\
\text { has become an important work for us. Objectively speaking, each market } \\
\text { player is facing difficulties. Enterprises have no revenue, but need to pay } \\
\text { rents and wages, it is not easy to survive. Practitioners' salary reduce, life } \\
\text { is not easy. We are making efforts to strengthen policy adjustment, and call } \\
\text { on all sectors of society to joint force together to get through the crisis. }\end{array}$ \\
\hline July 2021 & $\begin{array}{c}\text { Fo-16 } \\
\text { Restaurant owner }\end{array}$ & $\begin{array}{c}\text { In order to prepare for the peak tourism season in Lijiang, I have stored } \\
\text { more than 200,000 yuan food materials and trained nearly } 100 \text { service } \\
\text { personnel in my several hot pot restaurants, hoping to make up for last } \\
\text { year's losses. Who could have expected the rebound of the pandemic and } \\
\text { all the money have gone down the drain! }\end{array}$ \\
\hline July 2021 & $\begin{array}{l}\text { T-10, } \\
\text { Tourist }\end{array}$ & $\begin{array}{l}\text { After my son finished his college entrance examination, I brought him to } \\
\text { Lijiang. We both like music, so we spent most of the day in the folk bar in } \\
\text { the Old Town. Maybe it was because of the rainy season, there was very } \\
\text { few people, just us two and some staff, so I chatted with the resident } \\
\text { singers. It was not until evening that a table or two of guests came, so } \\
\text { lonely, completely lost the hustle and bustle of the past, much to my son's } \\
\text { disappointment. Well, it is all caused by the pandemic. }\end{array}$ \\
\hline
\end{tabular}

Recently, our travel agency only receives more than 20 individual tourists a day, and was not allowed team reception. It is said that there's a travel

August $2021 \quad$ TA-11, Middle managers of travel agencies

agency has been severely punished for violation of the rule, so each agency dare not act recklessly. The front-line staff have been dismissed home, with a basic salary of more than 1000 yuan a month. The rest of us are also idle panic. I have started to take bus or walk to work, at least can keep fit.

At the beginning of the pandemic, I was quite happy, thinking that I finally have a chance to rest. But later things went wrong, the pandemic continued and my transport line was shut down. I tried to do some other jobs, but they were not very good, and I cannot do them well, truly no occupation was easy. There are kinds of expenses in my family that can't be saved. If it continues any more, I have to consider selling my car. What I miss most now is tourists.

Since Yunnan Province suspended cross-provincial tourism activities on 5 August 2021, it is now September, and the Lijiang old town is still silent and quiet. From the big waterwheel to Yuhe Square, East Street, Sifang Square, Wuyi Street...Even the most lively and prosperous area in the past was also sparsely pedestrian, with a few people passing by occasionally, mostly locals. All kinds of businesses in the Old Town-shops, inns, restaurants, cultural and creative industries, most have been closed. Even the riverside restaurant that was supposed to be full at this time in previous years, is now empty, leaving only the waiters who brush their mobile phones or boring in a daze.

\subsubsection{Supply Side of the TSC}

(1) The service nature of tourism industry

First, the non-essential demand attribute of tourism products determines that it is easy to compromise on and abandon under the choice related to health. To some extent, tourism has the characteristics of luxury consumption, which suggests "money and leisure" but not necessity, which would be the first to be abandoned in the case of crisis events or economic contraction. Second, tourism service is a simultaneous process of production and consumption. The intangible and experiential nature of tourism service determines that tourism products, such as tickets and accommodation, cannot be stored. Without consumption in one day, the day's value will be lost, and the loss will be irretrievable. Third, tourism has the characteristics of scene, atmosphere and tourists' expectations, and thus it is difficult to form remote supply and consumption or to replace it through 
online virtual products. Fourth, regarding the "mobility from vulnerability" of the tourism industry, that is, the characteristics of high spatial mobility and group agglomeration, on the one hand, many tourism workers need to get close to tourists to provide services [43], such as restaurant waiters and entertainment workers; on the other hand, the tourism industry is centered on high mobility and social interaction, from destination to scenic spots, commuting, sightseeing, shopping, performance watching, communicating and chatting, which all mean a higher risk of infection [44].

Lijiang Yulong Tourism Co., Ltd., is the only A-share-listed tourism company in Lijiang, with stock code 002033. Its main business includes four sectors: cableway business (including three cableways-Yulong Snow Mountain, Spruce meadow and Yak meadow), Impression of Lijiang performing arts business, hotel operation (Lijiang Hefu Hotel Co., Ltd., including Intercontinental Hotel, Indigo Hotel and Ritz Hotel) and catering services, involved in the tourism supply chain of food, accommodation and travel. In 2020, the performance of Lijiang stock decreased by $70.51-58.23 \%$ year-on-year. Table 2 describes the major events of Lijiang Yulong Tourism Co., Ltd., since the outbreak of the novel coronavirus. Since the pandemic situation and prevention measures are essentially consistent with other parts of the country, it is representative of the tourism industry as a whole, reflecting the fluctuations of the pandemic since 2020 and the oscillation of the tourism enterprises brought about by this. Table 3 describes the operating income of each sector of Lijiang shares from 2018 to the first half of 2021. Considering that the impact of the pandemic on the tourism industry essentially started in 2020, the operating data of 2019 can be used as the reference data of normal years. From the core measurement indicators of tourism development-operating income figure, the income loss of tourism supply enterprises caused by the pandemic and the vulnerability of the supply side of the TSC can be directly felt.

Table 2. Major events of Lijiang Yulong Tourism Co., Ltd., since the outbreak of COVID-19.

\begin{tabular}{|c|c|c|}
\hline Time & Events & Background \\
\hline 25 January 2020 & $\begin{array}{l}\text { All businesses of the company were } \\
\text { suspended successively }\end{array}$ & $\begin{array}{l}\text { COVID-19 outbreak nationwide, government and } \\
\text { authorities' demands }\end{array}$ \\
\hline 20 February 2020 & $\begin{array}{l}\text { Combining the type and nature of the } \\
\text { business, the tourist reception work } \\
\text { resumed in an orderly manner in batches }\end{array}$ & $\begin{array}{l}\text { The pandemic had been effectively controlled, and the } \\
\text { overall situation had improved }\end{array}$ \\
\hline 1 March 2020 & $\begin{array}{l}\text { Indigo Hotel in Moonlight City of } \\
\text { Shangri-la opened for business }\end{array}$ & The pre-pandemic plan continued \\
\hline 22 May 2020 & $\begin{array}{l}\text { The business of the company was } \\
\text { fully resumed }\end{array}$ & $\begin{array}{c}\text { The pandemic situation tended to be stable, but due to the } \\
\text { impact of some domestic areas and foreign pandemic } \\
\text { situations, the number of tourists received had not } \\
\text { fully recovered }\end{array}$ \\
\hline August 2020 & $\begin{array}{l}\text { Seeking Cloud Vacation Hotel in Mosuo } \\
\text { Town opened to the public, which is a } \\
\text { Lugu Lake related project }\end{array}$ & $\begin{array}{l}\text { Continued to promote Lugu Lake related projects as the } \\
\text { "second main battlefield" }\end{array}$ \\
\hline 2nd half of 2020 & $\begin{array}{l}\text { The net profit returned to positive and } \\
\text { gradually improved }\end{array}$ & $\begin{array}{l}\text { Inter-provincial tourism recovery; driven by summer } \\
\text { vacation, Mid-Autumn Day, National Day }\end{array}$ \\
\hline 2021 Spring Festival & $\begin{array}{l}\text { Intra-provincial and inter-provincial } \\
\text { tours were restricted }\end{array}$ & $\begin{array}{l}\text { The pandemic was still spreading worldwide. Many } \\
\text { sporadic cases and even localized clustering pandemics had } \\
\text { occurred in China, and the pandemic prevention and } \\
\text { control situation was still severe and complicated. The } \\
\text { country advocated local Spring Festival celebrations }\end{array}$ \\
\hline 1st half of 2021 & $\begin{array}{l}\text { All businesses were opened and operated } \\
\text { normally, but the tourist reception } \\
\text { volume failed to fully recover }\end{array}$ & $\begin{array}{l}\text { The overall situation of the pandemic was under control but } \\
\text { was still affected by the situation in some areas in China } \\
\text { and abroad }\end{array}$ \\
\hline
\end{tabular}


Table 2. Cont.

\begin{tabular}{|c|c|c|}
\hline Time & Events & Background \\
\hline 5 August 2021 & $\begin{array}{c}\text { The company suspended inter-provincial } \\
\text { tourism activities }\end{array}$ & $\begin{array}{l}\text { There were medium and high-risk areas in Yunnan } \\
\text { Province, which required pandemic prevention and control }\end{array}$ \\
\hline 15 September 2021 & $\begin{array}{l}\text { Resuming inter-provincial } \\
\text { tourism business }\end{array}$ & $\begin{array}{l}\text { The medium and high-risk areas in Yunnan were cleared; } \\
\text { the Culture and Tourism Department of Yunnan Province } \\
\text { issued a notice on the restoration of inter-provincial tourism }\end{array}$ \\
\hline $\begin{array}{l}\text { 2021. National Day } \\
\text { Golden Week }\end{array}$ & $\begin{array}{l}\text { The flow of people had surged, and the } \\
\text { holiday economy was booming }\end{array}$ & $\begin{array}{l}\text { Driven by the National Day Golden Week, people's } \\
\text { long-suppressed tourism demand had been released }\end{array}$ \\
\hline 16 October 2021 & $\begin{array}{l}\text { The number of group tourists from } \\
\text { outside the province decreased sharply, } \\
\text { and the total number of tourists } \\
\text { decreased significantly }\end{array}$ & $\begin{array}{l}\text { The emergence of a "travel group transmission chain", a } \\
\text { new round of COVID-19 had spread to } 20 \text { provinces } \\
\text { in China }\end{array}$ \\
\hline
\end{tabular}

Source: Authors' collection.

Table 3. Operating income of each sector of Lijiang Co., Ltd., from 2018 to the first half of 2021.

\begin{tabular}{ccccccc}
\hline Main Business (RMB 100 Million) & $\mathbf{2 0 2 1 H 1}$ & $\mathbf{2 0 2 0 H 1}$ & $\mathbf{2 0 1 9 H 1}$ & $\mathbf{2 0 1 8 H 1}$ & $\mathbf{2 0 1 9}$ & $\mathbf{2 0 1 8}$ \\
\hline Revenue & 2.02 & 0.95 & 3.18 & 3.43 & 7.23 & 3.78 \\
\hline Cableway revenue & 0.98 & 0.51 & 1.59 & 2.05 & 3.901 \\
\hline Proportion of cableway revenue & $48.28 \%$ & $54.21 \%$ & $49.89 \%$ & $59.77 \%$ & $45.78 \%$ & $57.52 \%$ \\
\hline Impression Lijiang performance & 0.32 & 0.12 & 0.76 & 0.51 & 1.77 & 0.97 \\
\hline Proportion of performance & $15.71 \%$ & $12.90 \%$ & $23.85 \%$ & $14.83 \%$ & $24.48 \%$ & $14.31 \%$ \\
\hline Hotel business & 0.52 & 0.21 & 0.5 & 0.5 & 1.19 & 1.1 \\
\hline Proportion of hotel business & $25.79 \%$ & $22.23 \%$ & $15.74 \%$ & $14.63 \%$ & $16.46 \%$ & $16.22 \%$ \\
\hline Catering services & 0.06 & 0.02 & 0.07 & 0.09 & 0.27 & 0.12 \\
\hline Proportion of catering services & $2.94 \%$ & $2.50 \%$ & $2.09 \%$ & $2.51 \%$ & $3.73 \%$
\end{tabular}

Source: Authors' collection. ${ }^{1}$ Note: affected by the sharp drop of cableway price in October 2018; the proportion of cableway revenue in subsequent years decreased significantly.

\section{(2) Unique attributes of Tourism}

Firstly, tourism is seasonal. Some occupations are closely related to the low and peak seasons of tourism, such as tour guides, taxi/online car-hailing drivers and residents around tourist cities, who mainly rely on the provision of tourism-related products or services in peak seasons to obtain income. When the pandemic isolation period coincides with the peak season, it means that the low season comes after the isolation period, and the unemployment period becomes longer. Secondly, tourism also has social attributes. For certain social purposes, individuals usually have a strong preference to travel with relatives or friends so as to cultivate or promote the intimate emotional relationship with companions, reduce the boredom and loneliness of traveling alone or better adapt to the unfamiliar environment and resist various risks. When any member is restricted in movement, the whole group will give up the travel plan.

\section{(3) Stakeholders}

It is hard for tourism labor workers and resource providers to transfer knowledge, and therefore re-employment is difficult. Most tourism-related labor workers are not highly skilled, and thus the risk of losing benefits is greater, especially for the middle-aged and elderly women and temporary workers, who are the main part of the tourism labor force, with low education levels; they are disadvantaged groups in employment as it is very difficult to learn and master a new skill again for them. Finally, they either turn to other occupations with lower skill requirements or wait for the end of the pandemic and the recovery of tourism. 
4.1.2. Demand Side of the TSC

(1) GDP Decline

Tourism is an economic activity that depends on discretionary expenditure. As a result of the pandemic, large-scale enterprises, not only tourism-related enterprises but also many national production sectors, such as logistics and transportation, service trade, manufacturing and agriculture, have all been impacted by the suspension of business, enterprise revenue decrease, capital chain rupture, bankruptcy and labor force short-term unemployment, which will affect the economic income and living standard for a period of time in the future and reduce people's willingness to travel, consumption ability and consumer confidence.

(2) Tourists' risk perception and travel fear

During the pandemic development period, the increasing media reports and multiple other perception ways overlap with each other, causing tourists to be very sensitive to the perceived outside risks. Due to the lack of complete knowledge and information, individual tourists' perception of destination insecurity is often amplified or overgeneralized. For example, with the recurrence of the pandemic in Ruili city at the end of March 2021, many tourists from other provinces believed that the whole of Yunnan was unsafe and canceled their corresponding travel plans.

According to prospect theory, people's judgment or decision making under uncertainty depends on the gap between prospect/expectation and result. Tourists, out of fear and loss aversion of the insecurity caused by the dense population and risks or troubles of infection, isolation, scheduled loss, nucleic acid tests, Health Code discoloration, etc., brought by entering medium- or high-risk areas, would give up taking risks for tourism and continue to be inertial for a period of time to reduce travel.

(3) Destination atmosphere and tourist confidence

Whether the destination atmosphere is tense or relaxed has a great impact on tourists travel confidence. If the destination has more travel restrictions or health intervention measures such as traffic control, nucleic acid testing or advance reservation, there are fewer tourists. On the contrary, when destinations widely publicize tourism recovery and do not require additional travel conditions, tourists increase rapidly.

\subsubsection{Government Side}

As the guardian of people's safety and the maker of tourism policies, the government has issued restrictive policies to curb the spread of the pandemic, such as restricting movement and maintaining social distance, which have affected most tourism-related services, such as transportation, accommodation and catering. The pandemic has interrupted and impacted both the supply and demand of the tourism industry.

\subsubsection{Destination Industrial Structure}

The single industrial structure of small economies can also increase the vulnerability of the supply chain in tourism destinations. Lijiang is a small city with tourism as its pillar industry, whose economic volume is small and industrial structure is single. When affected by external impact, it has a weak ability to transfer risks through other channels, such as trade, manufacturing and high-tech industries, and the industrial way to digest surplus labor force is narrow, prolonging the time required for recovery.

\subsubsection{Extension and Long Tail of Supply Chain}

Influenced by COVID-19, tourism-related businesses such as conventions and exhibitions, conferences, wedding banquets, study tours, business tours, sports tourism and health care tourism have also been postponed or canceled. The impact of COVID-19 on the tourism industry also has a "long tail effect"; that is, after the end of the pandemic, it will take a period of transition (months or even a year) before the destination and tourists are 
fully liberalized for long-distance and inter-provincial tourism. It may take 6-12 months or even longer for the tourism industry to fully return to the normal level, and there is a certain lag in resuming activities.

To sum up, under the uncertain environment brought about by COVID-19, the inherent vulnerability of the TSC has been exposed. All levels and entities on the chain have been affected and disrupted by various factors, and how to survive is a big problem faced by all parties. Recovery and restart will take time and cannot be achieved overnight.

\subsection{TSC Resilience}

At the same time, from historical experience, tourism has recovered rapidly after pandemics such as Ebola, Middle East Respiratory Syndrome (MERS) and Severe Acute Respiratory Syndrome (SARS). There is also some encouraging industry resilience in the tourism industry (see core idea in Table 4), which could help it recover from the pandemic.

\subsubsection{Tourism Economic Environment}

Despite the severe impact of COVID-19, China still achieved positive economic growth in 2020, making it the only major economy in the world with positive growth. Under the uncertain environment, the long-term fine fundamentals of China's economy will not change, the supporting conditions for tourism development will continue to improve, the fact that tourism is still in the golden period of development will not change, and the prospect of tourism development is still good. With long-term and stable economic development, Chinese people have accumulated a certain economic foundation and stored enough "fat" to survive the pandemic winter.

Table 4. TSC resilience core idea.

\begin{tabular}{|c|c|c|}
\hline Time & Interviewee & Brief Narrative \\
\hline $\begin{array}{l}\text { January } \\
2021\end{array}$ & $\begin{array}{l}\text { TC-01, } \\
\text { Senior executive of Lijiang Co., } \\
\text { Ltd. }\end{array}$ & $\begin{array}{l}\text { First of all, I would like to thank the policy support. Since the outbreak of the } \\
\text { pandemic, relevant government departments have successively issued policies } \\
\text { to reduce or exempt the value-added tax and its surtax, real estate tax and land } \\
\text { use tax of the tourism industry for the whole year, as well as pension } \\
\text { insurance, unemployment insurance, work-related injury insurance and } \\
\text { medical insurance. Our Lijiang Co., Ltd. and subsidiaries have received a total } \\
\text { reduction of more than } 40 \text { million yuan, which is really a timely help to the } \\
\text { recovery of the company's performance. }\end{array}$ \\
\hline $\begin{array}{l}\text { February } \\
2021\end{array}$ & $\begin{array}{c}\text { TA-02, } \\
\text { Travel agency manager }\end{array}$ & $\begin{array}{l}\text { Now the novel coronavirus is serious, Yunnan has stopped inter-provincial } \\
\text { tourism. Almost all travel agencies in Lijiang have stopped operating, except } \\
\text { us. Without tourists, we train, study, plan routes to practice our internal skills. } \\
\text { Maybe the tourism will restart tomorrow, we must fully prepare for it. }\end{array}$ \\
\hline $\begin{array}{l}\text { February } \\
2021\end{array}$ & $\begin{array}{c}\text { F-21, } \\
\text { Villagers around Lijiang }\end{array}$ & $\begin{array}{l}\text { As the outbreak continued, our family has resumed agricultural planting and } \\
\text { bought dozens of sheep. We are farmers, it is not a problem to rely on farming } \\
\text { to make a living. There is no problem planting some land to feed our family, } \\
\text { and with dozens of sheep, we can still get on with life. We need to prepare for } \\
\text { the long-term "fight" against COVID-19. }\end{array}$ \\
\hline March 2021 & $\begin{array}{l}\text { TA- } 08 \text {, } \\
\text { Tour guide with } \\
\text { property in the Old Town }\end{array}$ & $\begin{array}{l}\text { In the past, I used to be a guide in the peak season, fishing or entertainment } \\
\text { with friends, life is easy and stress-free. However, there was suddenly no } \\
\text { group to take these two years, I gradually began to panic. My wife and I were } \\
\text { discussing to invest an express service node. You can't just sit there and wait. } \\
\text { The most important thing is not to be idle every day, or the spirit will } \\
\text { be decadent. }\end{array}$ \\
\hline April 2021 & $\begin{array}{c}\text { Fo-14, } \\
\text { Catering self-employed }\end{array}$ & $\begin{array}{l}\text { If I keep My restaurant open, there has few customers a day, almost no profit } \\
\text { after paying utilities; If we don't open, the rent will still be paid. Fortunately, } \\
\text { my husband's business of repairing electric vehicles is not bad, the cost of } \\
\text { school for our two children and the monthly payment of the house all depends } \\
\text { on him, so the life can still be maintained. }\end{array}$ \\
\hline
\end{tabular}


Table 4. Cont.

Time Interviewee Brief Narrative

Travel photography has never gotten better in 2021, and it is difficult to change careers, neither I have technology or capital. I was looking forward to the peak season of another year like everyone, but waiting for two years, the pandemic has gone back and forth, some stores have been closed and opened and closed. Last year, when there were no tourists, we tried to position the market into citizen-oriented services, taking some personal, parent-child and family

May 2021 TC-04, photos. Now the pandemic is gradually improving, we start taking pictures of ethnic minorities in the Old Town, which are very popular at affordable prices. In my spare time, I also do some wechat business, selling local specialties such as Lijiang black apples, soft-seed pomegranates and so on. Life is half poetic, half fireworks, we should live it worthy.

Although I am not a direct tourism practitioner, and my income has not been affected for the time being, but my main customers are from tourism industry.

I shoot videos, post official accounts, and write copywriters to help them attract tourists and increase visitor flow. Tourism has been depressed for a

June 2021 long time, if the lips are gone, the teeth will be cold, so I have been constantly adjusting my thinking. A while ago, I began to try to sell goods through live broadcast, delivering local catering specialties of Lijiang to outside. However, the competition is so fierce that it is difficult to enter a new industry. In constant reflection, I believe that tourism still needs to deeply cultivate culture and brand in order to remain invincible.

My family has a van and a business car to pick up and drop off tourists. In the

$\operatorname{Tr}-23$,

July 2021 Self-employed passenger transport

September 2021

TS-19, Scenic spot cleaner

17

September Notes of the project team previous peak season, my husband and I were so busy from morning to night that couldn't see each other, but it's too idle now. Fortunately, this is the season of wild mushrooms in Lijiang, he goes up the mountains to find fungus to sell, I continue to run the car. Since there are fewer tourists, it's too expensive to keep two cars, we're ready to sell one.

After the pandemic, I find one thing interesting. Many tourists come to our scenic spot bringing their own garbage bags. They not only stop littering, but also take garbage away. Once I saw a tourist taking his child to pick up rubbish thrown by others, I was so moved. The pandemic has made more and more tourists pay attention to protecting the environment.

As soon as I entered the Old Town, I felt that the flow of people near the big waterwheel and Yuhe Square has increased a lot. There are tourists taking pictures around the waterwheel, walking in groups of three or five, calling or answering the phone, sightseeing or resting, as if stepping back to the past, business as usual, time is good. Especially in the bar street, crowded with tourists and the atmosphere is excitement, giving people a long-lost sense of familiarity. The real-time big data shows that, at 8 p.m., the number of tourists is 14,853 , plus the resident population and working staff, the total number exceeded 24,000.

\subsubsection{Tourism Demand Side: Tourism Demand "Rigidity"}

As the top of the five happiness industries, tourism is an important industry to meet people's growing needs for a better life. According to the statistics bulletin of the Ministry of Culture and Tourism, the number of domestic tourists in China exceeded 6 billion in 2019 , with an average of 4.2 trips per person. To a certain extent, tourism has become a "rigid need" of modern people. Even under the pandemic situation, people's willingness to travel is still strong, and the number of tourists will rebound quickly when the related risk perception is weakened. The interview results and the surge of the number of tourists during the National Day in Lijiang mutually verified each other and jointly confirmed this point. 


\subsubsection{Government Organizational Measures}

After the outbreak of the pandemic, China's national and local governments have intensively introduced supportive policies and measures for damaged tourism-related enterprises, through tax policies such as tax reduction and exemption, tax deferral, flexible tax payment, bank financial support plans and the establishment of special support and subsidy funds, in order to ease the pressure on enterprises and help the industry overcome difficulties and gradually recover. The government has become an important player in the TSC.

\subsubsection{Tourism Supply Side}

\section{(1) Industry Self-Rescue and Innovation}

Although tourism enterprises suffered from the "pain" caused by the overall damage, they all actively carry out various self-rescue actions. For example, in Lijiang, companies implement priority allocation of resources for key businesses and core members, move to work online to save expenses, reduce investment to lower costs and strictly control risks. Scenic spots launched free tickets, coupon tickets and other marketing strategies to attract tourists. Travel agencies take advantage of the suspension to strengthen human resources training, practice their internal skills and accelerate "seeking change" activities. The whole industry explores new utilization of resources and new forms of business.

\section{(2) Short-Term Work Program and Flexible Temporary Employment}

In order to relieve the pressure on companies and employees at the same time, the Spanish Ministry of Labor launched the Short-term Employment Program, named ERTEs, which is "a flexible mechanism that allows companies that have a temporarily drop in production to reduce working hours or suspend contracts, rather than resorting to layoffs" [45]. On the premise that the companies undertake social responsibilities and the employees' occupational security, the large number of idle labor workers caused by the pandemic can be employed flexibly and temporarily, filling the employment gap in local agricultural and forestry products, takeout services, logistics and other life service industries to alleviate the employment pressure to a certain extent.

\section{(3) Circulation Capability of Closed-Loop Supply Chain in Local Market}

The domestic market, regional market and surrounding market are crucial to reduce the risk and vulnerability of the TSC. On the one hand, some of the tourism resources originally provided to tourists can be transformed to meet local needs; for example, travel photography can be transformed into family or personal photos for local residents. On the other hand, due to the periodicity of pandemic recovery, the goal of policy stability, the long tail of supply chain recovery, people's sense of local belonging, security psychology and budget constraints, people will turn to local to release tourism demand to some extent, such as domestic tourism, surrounding tourism, rural tourism, community tourism, VFR, etc. With the improvement of the regional economic system and the progress of local industries, the local supply chain has the ability to provide sufficient resources, including food, raw materials, service suppliers and talent, and further promote the local supply chain to become more active.

\section{(4) Mindfulness and Confidence of Tourism Practitioners}

The interview found that although there was pessimism and disappointment, most of the interviewees believed that the tourism industry would recover soon and expressed they would wait and persevere. Tourism practitioners have mindfulness, dedication, persistence, accumulation and innovation, would help tourists regain their confidence in traveling as soon as conditions permit and would bring tourism business restart and large-scale recovery (but not all) in a short time. Similar expressions such as "missing tourists" and "loving work more" were used many times by them, showing the active reflection of tourism practitioners after the pandemic. 


\section{(5) Technical Power}

Technology is a key power in creating tourism flexibility [46]. Big data technology has played an important role in accurately tracking tourists' behavior trajectory, screening coronavirus cases and close contacts, statistics of vaccination and predicting transmission trends. Robots, automation technology and artificial intelligence have made great contributions in reducing contact, maintaining safe social distance, reducing labor costs and enhancing flexibility. Gretzel et al. [47] proposed "six pillars of change in e-tourism research", putting forward that, in the future, the tourism industry will further explore and analyze the introduction of other appropriate technologies and accelerate the integration of AI, IoT and technologies related to location, navigation and UAV with the tourism industry so as to help realize industry reconstruction.

\subsubsection{Consensus and Coordination of Market Participants}

Participants in the TSC, such as tourism authorities, tourism associations, communities and residents, support each other based on the ecological awareness of symbiosis, coexistence and sharing and reach a consensus and action of "holding together to keep warm and overcome difficulties". For example, in Lijiang, villagers of Shuhe Ancient Town launched a Rent Reduction Action, while different types of service companies shared labor cooperation.

Taking the representative time window of September and October 2021, which covers the recovery of inter-provincial tourism, the Mid-Autumn Festival holiday and the National Day holiday, as an example, with the observation data of Lijiang Old Town at about 14:00 in the day and around 21:00 at night (see Figure 2) and the observation days of the tourist reception number that was recorded from the intelligent big data screen at the entrance of Yulong Snow Mountain (see Figure 3), cross-validation proves that since the resumption of inter-provincial tourism business in Yunnan Province on 9.15, the number of tourists continued to grow steadily; among them, there was a small increase from 9.19 to 9.21 during the Mid-Autumn Festival holiday and a sharp rise from 10.1 to 10.7 of the National Day, and a peak showed on 10.4 and a drop on 10.6, but there was still a significant increase compared with that before the holiday. Therefore, it can be seen that once the environment permits, the TSC will show rapid recovery growth and strong resilience. However, the recovery will not be achieved overnight, and there will be a long tail process. In addition, the role of holidays in the recovery and promotion of tourism should not be underestimated.

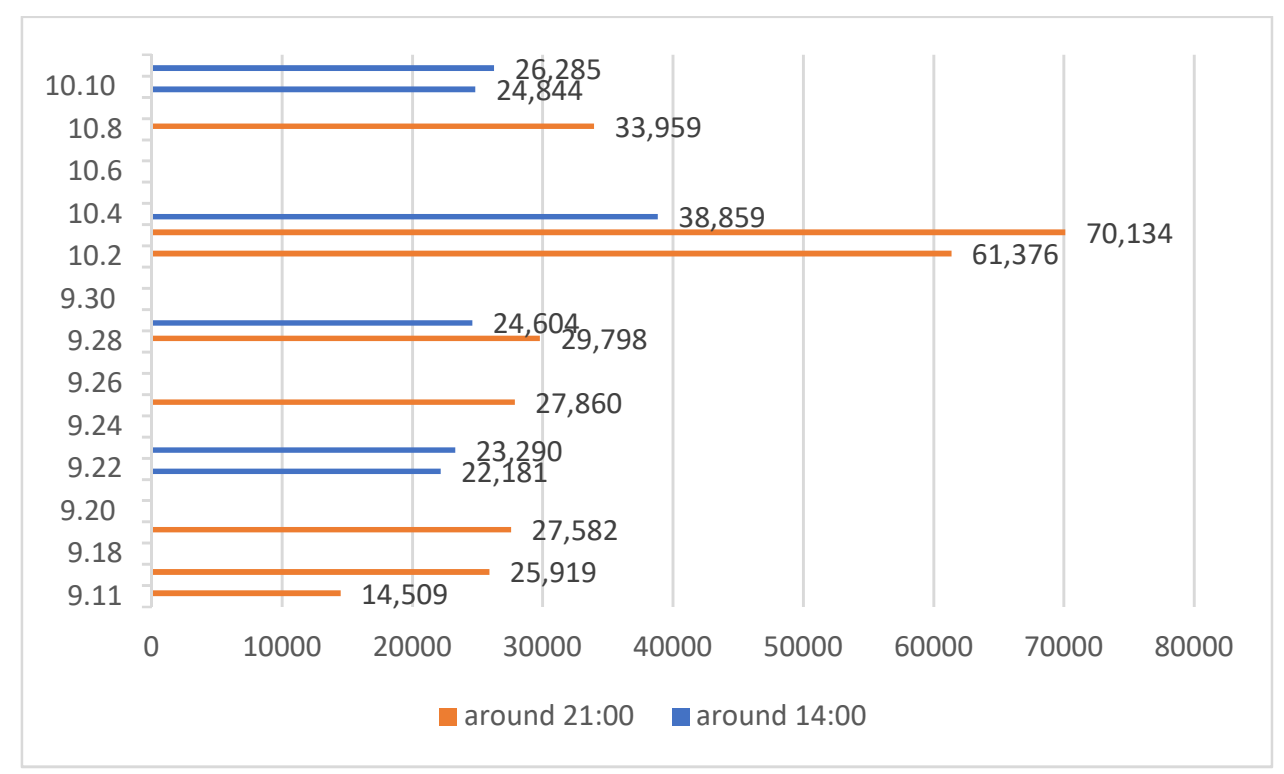

Figure 2. Changes in the number of tourists in Lijiang Old Town from September to October 2021. 


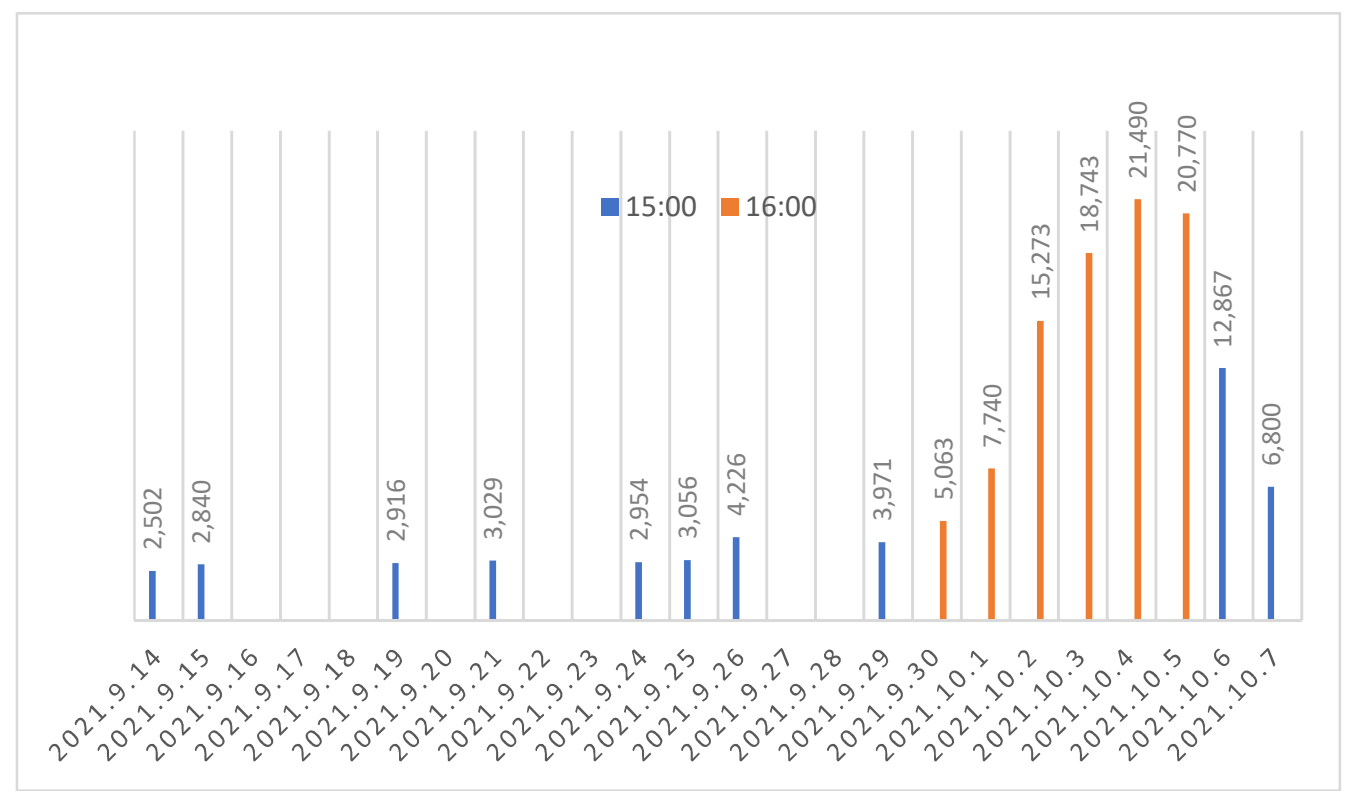

Figure 3. Changes in the number of tourists in Yulong Snow Mountain from September to October 2021.

In general, all tourism TSC actors are a unity of interests, sharing the local tourism market, interdependent and interactive. As the pandemic continues, the government, enterprises, employees and industry associations continue to increase their community awareness and seek change together, which enhances TSC resilience to get out of the crisis and move toward sustainability.

\section{Conclusions and Discussion}

In our work, we chose a city with tourism as its single pillar industry, Lijiang, in Yunnan, China, as a case site to investigate TSC vulnerability and TSC resilience under the background of the uncertain pandemic environment. By field observations, we recorded the diachronic states and changes of tourism in Lijiang during COVID-19 and conducted interviews with 168 tourism-related practitioners to obtain first-hand data. The CQR qualitative analysis method was adopted, focusing on narrative techniques. We also inserted two cases, Lijiang Co., Ltd., and Lijiang Old Town/Yulong Snow Mountain in the process, respectively representing the tourism enterprises and scenic spot stories, which not only made this paper more interesting but also formed a triangular verification with the results of the CQR analysis. Our conclusions are as follows:

(1) Under COVID-19, TSC vulnerability and resilience coexist. There are both vulnerability and resilience elements in the supply side, demand side, government side, etc. The embedding of the objective attributes of tourism and health emergencies has brought the vulnerability of the TSC under the uncertain environment. At the same time, behind the disruption caused by the pandemic, the TSC does not lack resilience, and there is a power of recovery and breeding the opportunity of innovation and change.

(2) All entities and individuals on the TSC have been affected and disrupted by various factors brought by COVID-19, which also prompted them to enhance their sense of community and cooperation. They work together, keep seeking ways to survive as well as prepare for tourism restart.

(3) Government plays an important role in TSC recovery. The rise and fall of tourism are closely related to the government's strict or relaxed travel policies, which affects the destination atmosphere, tourists' risk perception and travel confidence. The supporting policies are related to the survival of tourism enterprises and further affect employment and social stability. Propagation and marketing can effectively send 
positive signals to the market and avoid information asymmetry. All of these are critical to tourism sustainable rebuilding.

(4) The form of the TSC is being constantly innovated. Since offline tourism was blocked under the pandemic, online platforms such as microblogs, WeChat and short videos were developed as the "second scene" of tourism. Business models such as live broadcast, cloud travel and online commerce are constantly emerging, maintaining the positive interaction between the tourism supply side and the demand side, expanding new functions such as "tourism + social networking", "tourism + entertainment" and "tourism + shopping" and forming a new type of virtual and multifunctional agglomeration TSC. At the same time, new technologies are empowering the TSC. AI, big data, automation, 5G and other technologies are introduced by various actors of the TSC, which inject new vitality into the TSC material and energy cycle.

(5) Local TSC becomes more active. Under the pandemic prevention policy of "Do not go out of the city unless necessary", people will turn to the local market to release tourism demand to a certain extent, which will stimulate the local TSC, such as purchasing more food and raw material resources locally, establishing more supplier enterprises and employing more local labor workers, thereby accelerating the progress of the local industry. Meanwhile, due to the fear of intensive risks and policy restrictions, the popularity of some crowded scenic spots will be reduced, bringing more opportunities to the scattered and marginalized tourist destinations, such as rural tourism.

For a long time, the tourism industry has been in the inertial tendency of continuous expansion, triggering the industry's endless pursuit of growth, profit and expansion brought by tourism. The outbreak and continuity of COVID-19 provided an opportunity for all parties in the TSC to stop and reflect, redefine environment and safety, rethink occupation, life and health, cultivate new tourism pursuits and format innovation and pay attention to sustainable development issues such as climate change, social responsibility and well-being, ecological balance, etc., then restructure and transform the TSC to build a more stable and sustainable TSC system.

This study has several limitations. Our qualitative analysis was based on Lijiang's observation and interview methods, constrained by a qualitative study focusing on the experience of a few people and the limitations of a single case study, and the research results are not necessarily comprehensive and representative. Next, the conclusions of this paper can be further verified and expanded by combining the use of big data and a multi-case method. In addition, this paper focuses on January-October 2021, which is a short period. Further tracking the recovery and development of the tourism industry and TSC may lead to more discoveries and more complete conclusions.

Author Contributions: Conceptualization, H.B. and W.R.; methodology, H.B.; investigation, H.B. and W.R.; resources, H.B.; writing—original draft preparation, H.B.; writing-review and editing, W.R.; supervision, W.R.; funding acquisition, H.B. All authors have read and agreed to the published version of the manuscript.

Funding: This research was funded by Yunnan Philosophy and Social Science Planning Project, grant number QN2019008.

Institutional Review Board Statement: Not applicable.

Informed Consent Statement: Not applicable.

Data Availability Statement: The data presented in this study are available on request from the corresponding author, the data are not public available due to the interviewees are reluctant to disclose their identities and privacy.

Conflicts of Interest: The authors declare no conflict of interest. 


\section{Appendix A}

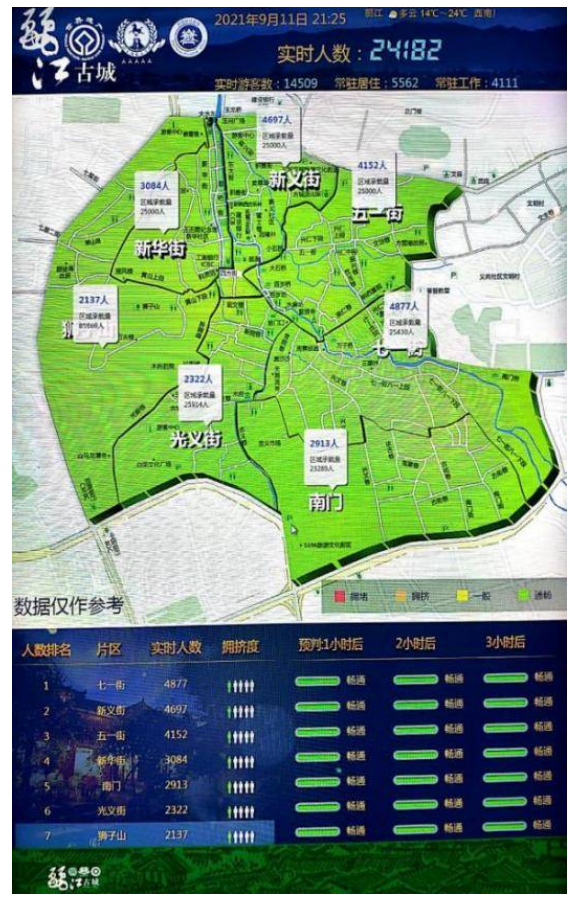

Figure A1. The intelligent big data screen in Lijiang Old Town (The figure on the top shows the real-time total number of tourists in Lijiang Old Town. The following mainly describes the real-time number of tourists in different areas, the degree of crowding, and the prediction; means full to capacity; means crowded; means normal; means comfort).

\section{Appendix B}

Table A1. Interviewees' occupation code in Tables 1 and 4.

\begin{tabular}{cc}
\hline Fo & Food industry \\
\hline Ac & Accommodation industry \\
\hline Tr & Transportation industry \\
\hline TA & Travel agency \\
\hline G & Government \\
\hline TC & Tourism company \\
\hline TS & Tourism scenic spot \\
\hline T & Tourist \\
\hline M & Media \\
\hline F & Farmer \\
\hline
\end{tabular}

\section{References}

1. Kumar, S.; Managi, S. Economics of Disasters and Climate Change. Process Integr. Optim. Sustain. 2020, 4, 481-502.1.

2. Sharma, R.; Shishodia, A.; Kamble, S.; Gunasekaran, A.; Belhadi, A. Agriculture supply chain risks and COVID-19: Mitigation strategies and implications for the practitioners. Logist. Res. Appl. 2020, 1-27. [CrossRef]

3. Prayag, G. Time for reset? Covid-19 and tourism resilience. Tour. Rev. Int. 2020, 24, 179-184. [CrossRef]

4. Tukamuhabwa, B.R.; Stevenson, M.; Busby, J.; Zorzini, M. Supply chain resilience: Definition, review and theoretical foundations for further study. Int. J. Prod. Res. 2015, 53, 5592-5623. [CrossRef]

5. Sheffi, Y.; Rice, B.J. A supply chain view of the resilient enterprise. MIT Sloan Manag. Rev. 2005, 47, 41-48.

6. Seville, E.; Opstal, V.D.; Vargo, J. A Primer in resiliency: Seven principles for managing the unexpected. Glob. Bus. Organ. Excell. 2015, 34, 6-18. [CrossRef] 
7. Niewiadomski, P. COVID-19: From temporary de-globalisation to a re-discovery of tourism? Tour. Geogr. 2020, 3, 651-656. [CrossRef]

8. Sharma, G.D.; Thomas, A.; Paul, J. Reviving tourism industry post-COVID-19: A resilience-based framework. Tour. Manag. Perspect. 2021, 37, 100786. [CrossRef]

9. Williams, A.M.; Balaz, V. Tourism risk and uncertainty: Theoretical reflections. J. Travel Res. 2014, 54, 271-287. [CrossRef]

10. UNWTO. Distribution Channels; World Tourism Organization: Madrid, Spain, 1975.

11. Scavarda, A.J.; Lustosa, L.J.; Scavarda, L.F. The tourism industry chain. In Proceedings of the Twelfth Annual Conference of the Operations Management Society (POM 2001), Orlando, FL, USA, 30 March-2 April 2001.

12. Page, S.J. Tourism Management: Managing for Change; Butterworth Heinemann: Oxford, UK, 2003.

13. Tapper, R.; Font, X. Tourism Supply Chains: Report of a Desk Research Project for the Travel Foundation; Leeds Metropolitan University, Environment Business \& Development Group: Leeds, UK, 2004.

14. Yilmaz, Y.; Bititci, U.S. Performance measurement in tourism: A value chain model. Int. J. Contemp. Hosp. Manag. 2006, 18, 341-349. [CrossRef]

15. Zhang, X.; Song, H.; Huang, G.Q. Tourism supply chain management: A new research agenda. Tour. Manag. 2009, 30, 345-358. [CrossRef]

16. Ke, L. An Initial Discussion on the New Pattern of the Supply Chain in Tourism Industry. Tour. Trib. 2006, 3, 30-33.

17. Dong, J.; Shi, Y.; Liang, L.; Wu, H. Comparative analysis of underdeveloped tourism destinations' choice of cooperation modes: A tourism supply-chain model. Tour. Econ. 2012, 18, 1377-1399. [CrossRef]

18. Ma, D.; Hu, J.; Yao, F. Big data empowering low-carbon smart tourism study on low-carbon tourism O2O supply chain considering consumer behaviors and corporate altruistic preferences. Comput. Ind. Eng. 2021, 153, 107061. [CrossRef]

19. Joshi, S. Social network analysis in smart tourism driven service distribution channels: Evidence from tourism supply chain of Uttarakhand, India. Int. J. Digit. Cult. Electron. Tour. 2018, 2, 255-272. [CrossRef]

20. Sigala, M. A supply chain management approach for investigating the role of tour operators on sustainable tourism: The case of TUI. J. Clean. Prod. 2008, 16, 1589-1599. [CrossRef]

21. Walker, B.; Salt, D. Resilience Practice: Building Capacity to Absorb Disturbance and Maintain Function; Island Press: Washington, DC, USA, 2012

22. Rice, B.J.; Caniato, F. Building a secure and resilient supply network. Supply Chain Manag. Rev. 2003, 7, 22-30.

23. Peck, H. Reconciling supply chain vulnerability, risk and supply chain management. Int. J. Logist. Res. Appl. 2006, 9, 127-142. [CrossRef]

24. Datta, P.P.; Christopher, M.; Allen, P. Agent-based modelling of complex production/distribution systems to improve resilience. Int. J. Logist. Res. Appl. 2007, 10, 187-203. [CrossRef]

25. Ponomarov, Y.S.; Holcomb, C.M. Understanding the concept of supply chain resilience. Int. J. Logist. Manag. 2009, 20, 124-143. [CrossRef]

26. Ponis, T.S.; Koronis, E. Supply chain resilience: Definition of concept and its formative elements. J. Appl. Bus. Res. 2012, 28, 921-930. [CrossRef]

27. Day, J.M. Fostering emergent resilience: The complex adaptive supply network of disaster relief. Int. J. Prod. Res. 2014, 52, 1970-1988. [CrossRef]

28. Hohenstein, N.-O.; Feisel, E.; Hartmann, E. Research on the phenomenon of supply chain resilience: A systematic review and paths for further investigation. Int. J. Phys. Distrib. Logist. Manag. 2015, 45, 90-117. [CrossRef]

29. Aslam, H.; Khan, A.Q.; Rashid, K.; Rehman, S.U. Achieving supply chain resilience: The role of supply chain ambidexterity and supply chain agility. J. Manuf. Technol. Manag. 2020, 31. [CrossRef]

30. Belhadi, A.; Kamble, S.; Jabbour, C.J.C.; Gunasekaran, A.; Ndubisi, N.O.; Venkatesh, M. Manufacturing and service supply chain resilience to the COVID-19 outbreak: Lessons learned from the automobile and airline industries. Technol. Forecast. Soc. Chang. 2021, 163, 120447. [CrossRef] [PubMed]

31. Arbulú, I.; Razumova, M.; Rey-Maquieira, J.; Sastre, F. Measuring risks and vulnerability of tourism to the COVID-19 crisis in the context of extreme uncertainty: The case of the Balearic Islands. Tour. Manag. Perspect. 2021, 39, 100857. [CrossRef]

32. Trabucco, M.; De Giovanni, P. Achieving Resilience and Business Sustainability during COVID-19: The Role of Lean Supply Chain Practices and Digitalization. Sustainability 2021, 13, 12369. [CrossRef]

33. Seuring, S. The rigor of case study research in supply chain management. In Proceedings of the 18th Annual Conference for Nordic Researchers in Logistics of NOFOMA, Oslo, Norway, 8-9 June 2005; Jahre, M., Persson, G., Eds.; pp. 1-16.

34. Sanabria Díaz, J.M.; Aguiar Quintana, T.; Araujo Cabrera, Y. Tourist Renewal as a Strategy to Improve the Competitiveness of an Urban Tourist Space: A Case Study in Maspalomas-Costa Canaria. Sustainability 2020, 12, 8775. [CrossRef]

35. Yin, R.K. Case Study Research: Design and Methods, 2nd ed.; Sage: Newbury Park, CA, USA, 1994.

36. Yan, S.; Mimi, L.; Shaowua, L. A Narrative Analysis of Destination Decision Making Process of Millennium Outbound Tourists: The Role of Opportunity-driven Decision Making. Tour. Trib. 2021, 36, 92-103.

37. Dey, I. Qualitative Data Analysis: A User-Friendly Guide for Social Scientists; Routledge: London, UK, 1993 ; p. 285.

38. Eisner, E.W. The Enlightened Eye: Qualitative Inquiry and the Enhancement of Educational Practice; Macmillan: New York, NY, USA, 1991.

39. Heppner, P.P.; Kivlighan, D.M.; Wampold, B.E. Research Design in Counselling; Brooks Cole: Pacific Grove, CA, USA, 2008. 
40. Hill, C.E.; Thompson, B.J.; Williams, E.N. A guide to conducting consensual qualitative research. Couns. Psychol. 1997, 25, 517-572. [CrossRef]

41. Hill, C.E.; Knox, S.; Thompson, B.J.; Williams, E.N.; Hess, S.A.; Ladany, N. Consensual qualitative research: An update. J. Couns. Psychol. 2005, 52, 196-205. [CrossRef]

42. Turner, B.L., II; Kasperson, R.E.; Matson, P.A.; Mc Carthy, J.J.; Corell, R.W.; Chirstensen, L.; Schiller, A. A framework for vulnerability analysis in sustainability science. Proc. Natl. Acad. Sci. USA 2003, 100, 8074-8079. [CrossRef] [PubMed]

43. Sönmez, S.; Apostolopoulos, Y.; Lemke, M.K.; Hsieh, Y.C.J. Understanding the effects of COVID-19 on the health and safety of immigrant hospitality workers in the United States. Tour. Manag. Perspect. 2020, 35, 100717. [CrossRef]

44. Neuburger, L.; Egger, R. Travel risk perception and travel behavior during the COVID-19 pandemic 2020: A case study of the DACH region. Curr. Issues Tour. 2020, 24, 1003-1016. [CrossRef]

45. Felgueroso, F.; Jansen, M. Una Valoraci' on de los ERTE Para Hacer Frente a la Crisis del COVID-19 en Base a la Evidencia Empíricay Desde una Perspectiva Comparada (No. 2020-06); FEDEA: Madrid, Spain, 2020.

46. Hall, M.; Scott, D.; Gossling, S. Pandemics, transformations and tourism: Be careful what you wish for. Tour. Geogr. 2020, 22, 577-598. [CrossRef]

47. Gretzel, U.; Fuchs, M.; Baggio, R.; Hoepken, W.; Law, R.; Neidhardt, J.; Xiang, Z. e-Tourism beyond COVID-19: A call for transformative research. Inf. Technol. Tour. 2020, 22, 187-203. [CrossRef] 